\title{
A High Degree of Cleanliness of the Electric Air Supply Valve Design
}

\author{
Luo Hu \\ Mechanical and Information Engineering Department, China University of Mining and Technology, 100083, Beijing, China
}

\begin{abstract}
This paper discuss an new type servo valve, aiming at two main defects of performance of globe valve which are commonly used in mine safety cabins in China, in order to bring up a better solution to replace old valves. On one hand, most of globe valves are manual ball valves whose oxygen content cannot be accurately controlled and can only be estimated by human respiratory sense, ended in large errors[1]. On the other hand, although in market there is oxygen-concentration test equipment, the separation of valve components and manual control switch, leads to complicated procedures and management inconvenience. For solving these problems, an innovative valve mechanical structure is designed, with its servo system bringing up. The proportional valve measures the room oxygen concentration in real time, closed-loop controlling of electric valve-opening, so that the concentration of oxygen in the ambient air is maintained at a desired level. The principle of this implementation is that an explosion-proof motor drives the roller cam to convert valve core into reciprocating linear motion, separating O-ring and valve body end-face to control valve core achieving the opening and closing functions. Since there is no relative motion between O-ring and valve body, it definitely avoids problems of uncontrollable particles caused by abrasion and ensures a high cleanliness of flow path. In addition, electric servo valve controls the precise oxygen concentration, automatically. Compared with manual air supply valve, this valve has advantages of high cleanliness, reliable sealing, easy assembly, maintenance, and automation. It provides a new technical approach for design of special industrial and mining value.
\end{abstract}

\section{Introduction}

In cases of dangerous situations such as coal mines and other special occasions during operation, to ensure the safety of workers, it needs to set up an escape safety cabin for temporary sheltering and waiting for rescue. In its life support system, the Oxygen and Nitrogen gas supply lines need supply valves to maintain the gas balance in the cabin. Manual valve switches do not have the function of automatic maintaining the gas concentration balance. The oxygen concentration can only be determined by human breath[2], ended in big error of Oxygen concentration. And the oxygen concentration may become too low to breath or too dense to breath. At the same time, when the number of valves gets too large, opening and closing the manual valve one by one is not only time-consuming but also more prone to safety accidents. Therefore, it is necessary to propose an electric servo air supply valve[3].

The structure of the current valves are main two kinds: filling ball valve and plug valve. For filling ball valve, although its seal property is reliable, at the switch seal interface, close contact with each other relative rotational friction, resulting in wear and tear, excessive wear debris, affect gas cleanliness requirements, while human respiratory system gets a detrimental effect. Plug valves have been widely and successfully used in the pneumatic and hydraulic industries owing to its oil's reduced friction. However, due to the absence of a lubricant in a high-purity gas environment, there is a possibility of the O-ring being cut, causing a sudden leak failure, which leads this kind of valve to be used less and less. Diaphragm shut-off valve can control the excess material generated, but it's not suitable for escape chamber small flow of gas delivery occasions[4]

With the gradual improvement of the cleanliness standard, the original cut-off valve is difficult to meet the high cleanliness and automation requirements. Therefore, it is urgently needed to develop a new type of servo valve to overcome the above insufficiency of the gas supply valve. The proposed new type of electric gas supply servo valve can realize the sealing function by compressing and separating movement between the sealing interfaces to prevent the generation of particles. High cleanliness features, automatic opening and closing and high reliability to maintain the balance of gas supply.

\section{New fast opening and closing valve design}

\subsection{Electric supply valve technical indicators and technical requirements}

According to the general requirements of the safety cabin pipeline conditions, the main technical indicators are shown in Table 1.

Technical requirements: This is a low-pressure gas supply oxygen valve, and has a quick opening and closing function, opening and closing the frequency of moderate. As the gas supply to the body to breathe, so the 
supply of gas is not allowed to produce more than $0.1 \mathrm{~mm}$ particles to meet the cleanliness standards. Due to the output of pure oxygen gas, there is a mandatory restriction on the gas flow rate for safety reasons. The flow path surface must have inert oxygen[5]. The technical route is shown in Figure 1.

\subsection{Electrical oxygen valve technology principles and characteristics}

\subsubsection{Drive components technical principle}

Driven by motor reducer Eccentric cam guide rod and the spool reciprocating linear motion, when the eccentric cam, the valve ring to move the valve ring to separate the valve body to open, as shown in Figure 1. When the reducer shaft is rotated 180 degrees, it is the maximum open position, and the valve is closed when rotated 180 degrees again.

\subsubsection{The original motivation features}

The prime mover adopts a motor driven by a reducer rather than a direct motor. On the one hand, the reducer increases the operating torque so that a smaller motor can drive it. On the other hand, it is not easy to slip when the output shaft has a large torque when the device is not running, it can effectively prevent it from inverting.

Table 1. Electric oxygen valve technical indicators

\begin{tabular}{|c|c|c|}
\hline Physical quantity & Symbol & Value (unit) \\
\hline Work pressure & $\mathrm{P}$ & $0.1 \mathrm{MPa}$ \\
\hline Max-pressure & $\mathrm{P}_{\max }$ & $0.5 \mathrm{MPa}$ \\
\hline Output flow & $\mathrm{Q}_{1}$ & $100 \sim 400 \mathrm{ml} / \mathrm{min}$ \\
\hline Internal leakage rate & $\mathrm{q}_{1}$ & $\leq 10^{-3} \mathrm{~Pa} \cdot \mathrm{L} / \mathrm{s}$ \\
\hline Leakage rate & $\mathrm{q}_{\mathrm{o}}$ & $\leq 10^{-4} \mathrm{~Pa} \cdot \mathrm{L} / \mathrm{s}$ \\
\hline Control method & $/$ & $\mathrm{S} / \mathrm{W}$ \\
\hline
\end{tabular}



Figure 2a. Electric valve flow path close state 1: Sealing ring 2: Guide shaft 3: Disc spring 4: Roller 5: Valve body 6: Groove

7: Dial 8: Motor 9: PC 10: Oxygen detector

\subsubsection{Seal compression amount and size chain compensation}

The amount of O-ring compression is a key parameter in this design. The end seal compression ratio is generally $22 \% \sim 26 \%$, which determines the compression range. Using the principle of the shortest dimension chain to control the compression rate can greatly reduce

\begin{tabular}{|c|c|c|}
\hline Rated current & $I$ & $1 \sim 2 \mathrm{~A}$ \\
\hline Rated voltage & $V$ & $12 \mathrm{~V}$ \\
\hline Medium & $/$ & Oxygen, nitrogen \\
\hline Switching time & $t$ & $\leq 1 \mathrm{~s}$ \\
\hline
\end{tabular}

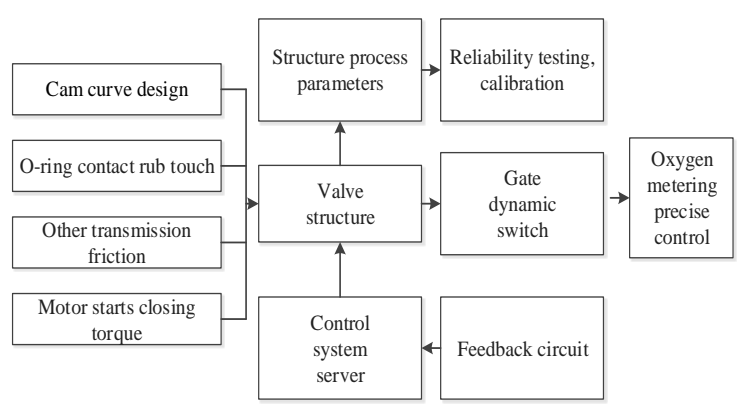

Figure 1. Technical route

\subsubsection{Contact seal features}

Through the sealed interface in situ movement between the compression and separation to achieve sealing function, no relative rotation between the seal vice or sliding to prevent the generation of particles to meet the high cleanliness characteristics.

\subsubsection{The reliable sealing pair O-ring features}

The O-ring 1 is fitted on the guide rod and the end face of the valve body to form a sealing pair, the sealing pair interface only exists reciprocating movement, the contact process is the O-ring compression deformation process, the state is the same as the static seal on the face. To overcome the plug valve rotation process rotary seal with the filler ball contact rotating friction and wear bring particulate matter, which is shown in Figure $2 \mathrm{a}$ and $2 \mathrm{~b}$.

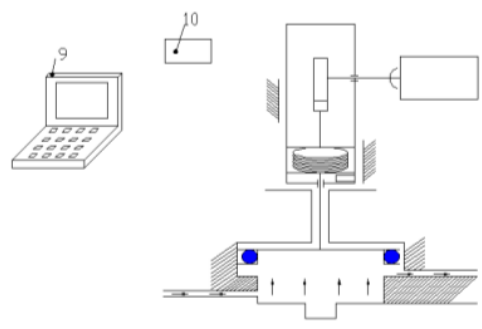

Figure 2b. Electric valve open

the processing cost. As shown in Figure 3, the distance between the k-plane of the valve core and the m-plane of the valve body is the amount of compression and the increasing ring L3 and the reduction ring L2 constitute the smallest size chain. Only controlled by two size chains easy to guarantee, which is shown in Fig3. To ensure the value of the design choice eccentricity e is greater than the amount of compression; that $\mathrm{e}$ $=(0.2 \mathrm{~mm} \sim 0.3 \mathrm{~mm})$, while avoiding rigid transport interference, the valve core and the guide rod to 
increase the stiffness of the pressure Spring 2, the stiffness of the valve core seal compression stiffness of 5 to 8 times. This avoids interference with the rigid body and reduces machining accuracy while also ensuring the amount of compression required for the seal[6].
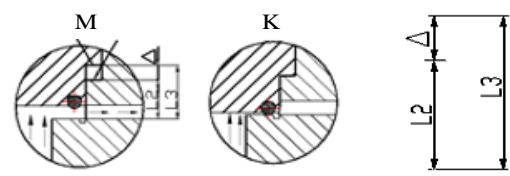

Figure 3. Ring size chain diagram

L1: Seal the amount of compression; L2: body step size; L3: spool step size

\subsubsection{System action status}

The system operation status is as shown in Figure 3 and the system passes through the oxygen concentration detection sensor in the mine environment, oxygen concentration data monitoring, feedback data, real-time and target oxygen concentration contrast so poor, the deviation of the valve to open and close the size of the dynamic control at the same time, the system designed by the valve high The accuracy of the linear potentiometer to promote the displacement of the last level of the spool to measure the known oxygen content of the spool displacement of the worst comparison, the system of these two deviations after the integration of the valve opening and closing control, In order to achieve a more accurate control of the ambient oxygen content, which is shown in Figure 4.

\begin{tabular}{|c|c|c|c|c|}
\hline \multirow{2}{*}{$\begin{array}{c}\text { Test oxygen } \\
\text { concentration }\end{array}$} & The system in which the target & \multirow{2}{*}{$\begin{array}{l}\text { Valve dynamic } \\
\text { opening }\end{array}$} & To achieve the dynamic & \multirow{2}{*}{ Dynamic valve closing } \\
\hline & $\begin{array}{l}\text { oxygen concentration is not } \\
\text { reached is in an unbalanced state }\end{array}$ & & $\begin{array}{l}\text { balance of the predetermined } \\
\text { concentration system }\end{array}$ & \\
\hline
\end{tabular}

Figure 4. System operation status

\section{Calculation and check}

\subsection{Motor reducer starting torque calculation}

This chapter established the oxygen shut-off valve statics model shown in Fig 5. In the establishment of its static model, consider the rolling contact friction cam, guide rod sliding friction, gas force and seal pressing force. The pressing force of the seal ring is the critical boundary condition to be calculated. The relationship between the compression amount and the pressing force of the rubber seal ring is obtained through the finite element method[7]. The relationship between the rotational resistance torque and the working resistance torque is as follows:

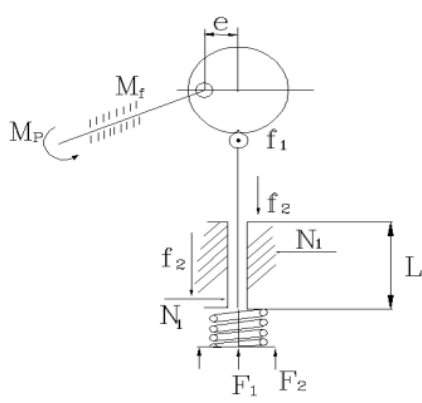

Figure 5. Oxygen servo driving mechanism static model
Table 2. Oxygen servo valve transmission parameter

\begin{tabular}{|c|c|c|}
\hline Symbol & Physical meaning & Value(unit) \\
\hline $\mathrm{e}$ & Cam eccentricity & $3 \mathrm{~mm}$ \\
\hline $\mathrm{r}$ & Cam radius & $12 \mathrm{~mm}$ \\
\hline $\mathrm{P}(\max )$ & $\begin{array}{c}\text { Cam seals to withstand the } \\
\text { maximum pressure }\end{array}$ & $2 \mathrm{Mpa}$ \\
\hline $\mathrm{d}$ & Shaft diameter & $10 \mathrm{~mm}$ \\
\hline $\mathrm{L}$ & Guide rod length & $60 \mathrm{~mm}$ \\
\hline$\mu_{1}$ & Roller cam friction coefficient & 0.05 \\
\hline$\mu_{2}$ & $\begin{array}{c}\text { Guide rod and sliding friction } \\
\text { coefficient }\end{array}$ & 0.3 \\
\hline$\mu_{3}$ & $\begin{array}{c}\text { Guide rod and valve body } \\
\text { friction coefficient }\end{array}$ & 0.3 \\
\hline
\end{tabular}

\subsection{Relationship between O-ring-compression and compression pressing force}

The rubber O-ring was selected to have a Shore hardness of 75 degrees and was treated with a large elastic deformation. The Mooney model was selected for the material properties to estimate using the finite element contact analysis[8]. The two sides of the O-ring were rigid geometrical boundaries and 1/4 Meshing as an axisymmetric analysis model, shown in Figure 6a, the millimeter unit system, O-ring cross-section diameter of $2.65 \mathrm{~mm}$, an inner diameter of $8 \mathrm{~mm}$, the amount of compression $0 \sim 1 \mathrm{~mm}$, obtained Cauchy stress during compression, contact compression and compression Relationship between. Fig6b Cauchy equivalent cloud chart, Figure 5c 25\% compression rate compression force $70 \mathrm{~N}$. 


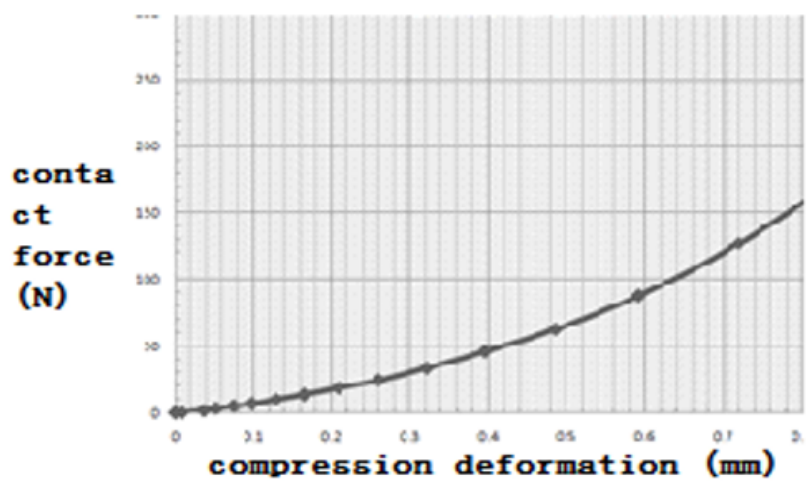

Figure 6a. Cauchy stress ring

Calculated by the handle open torque $0.4 \mathrm{Nm}$, here to $0.8 \mathrm{Nm}$, if the reducer gear ratio to take 3.6 , the motor output torque 0.22 , you can choose 28 stepper motor, if

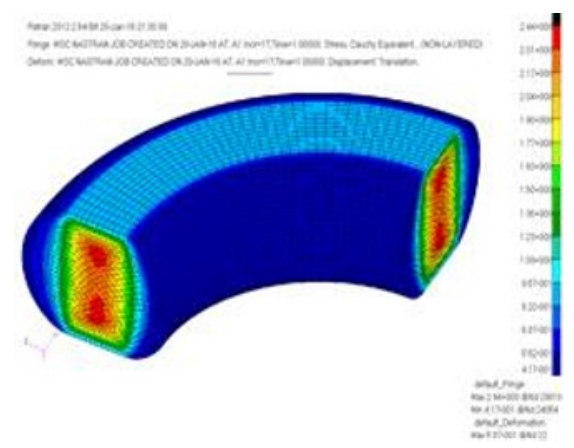

Figure 6b. Contact force - compression deformation curve

Table 3. Torque calculation formula

\begin{tabular}{|c|c|c|c|c|}
\hline Symbol & Physical meaning & Expression & Value & Unit \\
\hline $\mathrm{F}_{1}$ & Gas force & $F_{1}=\pi \mathrm{d}^{2} P_{\max } / 4$ & 39 & $\mathrm{~N}$ \\
\hline $\mathrm{F}$ & Disc spring max-pressure & $F_{2}=\mathrm{k} \Delta$ & 20 & $\mathrm{~N}$ \\
\hline$/$ & Sealing force & Finite element analysis results & 70 & $\mathrm{~N}$ \\
\hline $\mathrm{f}_{1}$ & Cam roller friction & $\mu_{1}\left(F_{1}+F_{2}+f_{2}\right)$ & 3 & $\mathrm{~N}$ \\
\hline $\mathrm{F}_{2}$ & $\begin{array}{c}\text { Eccentric wheel above guide rod } \\
\text { normal force }\end{array}$ & $F_{1}+F_{2}+f_{1}+f_{2}$ & 119 & $\mathrm{~N}$ \\
\hline $\mathrm{f}_{2}$ & Guide sliding friction & $f_{2}=2 \mu_{3} F_{2} \cdot e / L$ & 7 & $\mathrm{~N}$ \\
\hline $\mathrm{M}_{\mathrm{h}}$ & Reducer output torque & $F_{2} \cdot \mathrm{e}$ & 0.4 & $\mathrm{Nm}$ \\
\hline $\mathrm{N}$ & Motor speed & $\mathrm{f} \cdot \mathrm{i}$ & $/$ & $\mathrm{R} / \mathrm{s}$ \\
\hline
\end{tabular}

$\mu_{1}, \mu_{2}$ : Poisson's ratio of cam and roller material,

\subsection{Cam parameters design and check}

Cam and roller contact (cam pair) at the normal load, in units of N. Structure operation diagram is as shown as Figure 7, simplified model of cam transmission.



Figure 7. Simplified model of cam transmission

$$
\sigma_{\mathrm{H}}=\frac{\mathrm{F}}{\pi \mathrm{L}} \sqrt{\frac{\frac{1}{\rho_{1}}+\frac{1}{\rho_{2}}}{\frac{1-\mu_{1}^{2}}{\mathrm{E}_{1}}+\frac{1-\mu_{2}^{2}}{\mathrm{E}_{2}}}}
$$

$\rho_{1} 、 \rho_{2}$ : The radius of curvature of the actual profile of the cam and the roller radius in $\mathrm{mm}$.

$L$ : Cam and roller contact line length. the spool reciprocating frequency of 1 , the motor speed $3.6 \mathrm{r} / \mathrm{s}$. respectively.

$E_{1}, E_{2}$ : Respectively elastic modulus of cam and roller material quantity $\mathrm{MPa}$.

Where, $\mathrm{b}=0.005 \mathrm{~mm}, \mathrm{~F}=112 \mathrm{~N}, \sigma_{\mathrm{H}}=150 \mathrm{~N}$ is calculated $108 \mathrm{MPa}$, less than the allowable stress to meet the design requirements.

Curves of the movement of the law to determine: As the cam lift away from the displacement $x=x_{0}+\mathrm{e} \times \cos \theta$, the sealing ring diameter of $2.67 \mathrm{~mm}$, the particle center $x_{0}$ from the valve body end is $1.34 \mathrm{~mm}$, but due to the compression rate of $15 \%$ The body end surface is $1.12 \mathrm{~mm}$, the cam is eccentric from the nearest minute groove with the shortest farthest to prevent the motor from starting is free to reverse[9].

\subsection{Servo valve oxygen flow calculation}

Assuming that the motor speed is $\mathrm{n} \mathrm{r} / \mathrm{m}$, the radial $R_{T}$ $\mathrm{mm}$, displacement of the guide shaft is related to the time:

$$
s=R_{T}+e \sin \varphi t=R_{T}+e \sin \frac{2 \pi n}{60} t
$$


It beginning of the rising phase of the guide shaft, the oxygen outflow area is shown in Figure 8 below: where 1 is the outlet of the valve and 2 is the end surface of the guide shaft.



Figure 8. Radial displacement of guide shaft and ventilation cross section

\section{Oxygen servo valve structure design}

\subsection{Structure design}

Oxygen supply structure of the valve as shown in Figure 9, the valve body as a whole structure, the bottom of the extension of the installation interface, that is, with a hole for the valve fixed, and the base vertical holes above the pipeline connection with the entrance and exit. Handle and reducer 11 layouts above the valve body, and the valve body perpendicular to the handle and valve body are dust cover. The valve core 5 is designed as a fitting groove structure, and a disc spring 6 is embedded between the valve core 5 and the guide shaft 7 through the fitting of the fitting groove so as to avoid the rigid motion interference. The disc spring 6 is provided with a radial groove on the outer circumference to release the rigidity and increase the deformation of the disc spring. The action of the stop block prevents the disc spring from becoming unstable and can reduce the precision of the sleeve and the guide bar. O-ring 2 will be fixed by spinning the valve dovetail groove to prevent its fall off, and then through the reducer output shaft rotation to achieve the valve switch. Open the valve overall height of $174 \mathrm{~mm}$, $114 \mathrm{~mm}$ center distance shown in Figure 9, to achieve the valve lightweight design.

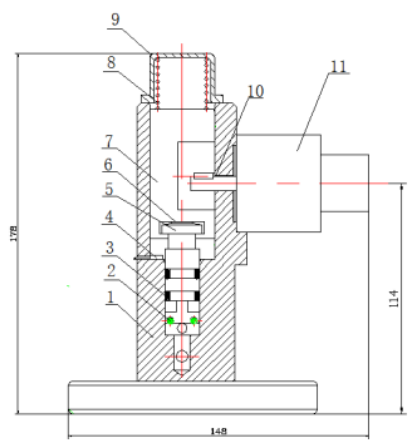

Figure 9. Oxygen servo valve structure

1: Body 2: Seal ring 3: Secondary seal 4: Linear potentiometer 5: Spool.6: Disc spring 7: Guide shaft 8: Spring 9: Bonnet 10: Gear unit output shaft 11: Gear unit

\section{Valve servo system}

\subsection{Servo valve controllable range}

To find out if the valve end is in contact with the valve body and achieve a $15 \%$ compression ratio to maintain seal reliability, introduce a linear potentiometer to measure spool travel distance as shown in the dimension chain diagram in Figure 10.

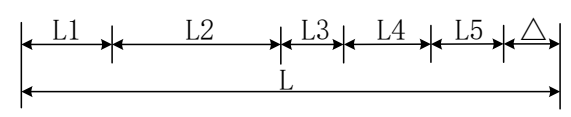

Figure 10. Schematic test system

L1: ring compression, L2: the length of the valve body and the length of the valve body, L3 disc spring length, L4 and the sum of the radius of the roller and the L5 potentiometer distance $\Delta$ for machining errors between parts, calculated L5 is within the range of ( $2 \pm$ $0.2) \mathrm{mm}$ and $(8 \pm 0.2) \mathrm{mm}$, but for practical verification and better control performance, a linear potentiometer is introduced to measure the reciprocating movement of the spool.

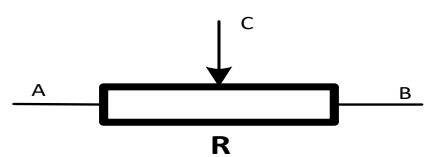

Figure 11. High precision linear potentiometer circuit model

Linear potentiometer installation design shown in Figure 9, at 4th position; Linear potentiometer test principle shown in Figure 11, A and B are respectively connected to the reference voltage positive and negative, C-terminal angle simulation voltage output.

The corresponding relationship between the voltage signal of the linear potentiometer sensor and the linear displacement signal is (3), where the line displacement of the $\mathrm{C}$ port to ground represents the output value of the analog voltage signal, indicating the linear displacement of the linear potentiometer, that is, the displacement of the spool, Corresponding to the position of the $\mathrm{C}$ sliding terminal on the resistor $\mathrm{R}$. The proportional coefficient of the linear potentiometer is determined by the relation (4), is the ratio of the reference voltage applied to the sensor to the maximum detectable line distance.

$$
\begin{aligned}
& V_{\text {out }}=K_{p} L \\
& K_{L}=V_{\text {ref }} / L_{\max }
\end{aligned}
$$

The C-terminal analog voltage directly to the Atmel company Atmega-8-bit microcontroller analog digital $\mathrm{AD}$ interface, the $\mathrm{AD}$ precision of the microcontroller is 10 , read the analog voltage value through the conversion relationship (5) converted to obtain spool displacement, that is realized with a linear potentiometer reciprocating distance measurement.

$$
L=A D \cdot L_{\max } / 2^{10}
$$


The range of values measured by the analysis of Figure 11 is: $L=A D \cdot L_{\max } / 2^{10}=(2 \pm 0.2,8 \pm 0.2) \mathrm{mm}$.

Real-time monitoring of the spool through the actual distance from the actual concentration of oxygen content in the room, two quantities at the same time return back to the Atmeg8 microcontroller; Then the controller will make data, which is feedback by the dual potentiometer, integrated to give out command of motor controlling signal to drive the angle rotating system.

\subsection{Servo control system}

For accurate control of indoor oxygen concentration, the design of double closed-loop control system, the system input target oxygen concentration of $R_{i n}(\mathrm{~s})$
Drive amplification circuit amplification factor is $k_{p}$; Permanent magnet brush motor transfer function is $G_{0}(\mathrm{~s})$; Reducer reduction ratio $k_{i}$; Groove roller transfer function is $G_{1}(\mathrm{~s})$, the output displacement of $x_{p}$; Displacement $x_{p}$ and oxygen concentration $Q_{\text {out }}(\mathrm{s})$ between the transfer function $G_{2}(\mathrm{~s})$; System output oxygen flow $Q_{\text {out }}(\mathrm{s})$; And indoor oxygen concentration of $R_{\text {out }}(\mathrm{s})$ between the relationship of $G_{3}(\mathrm{~s})$; The groove wheel output displacement $x_{p}$ and indoor oxygen concentration $R_{\text {out }}(\mathrm{s})$ feedback to the controller at the same time, the controller algorithm data fusion system output control, dynamic adjustment valve opening and closing state, in order to achieve better results. That is, the transfer function and block diagram of the control system step by step are shown in Figure 12.

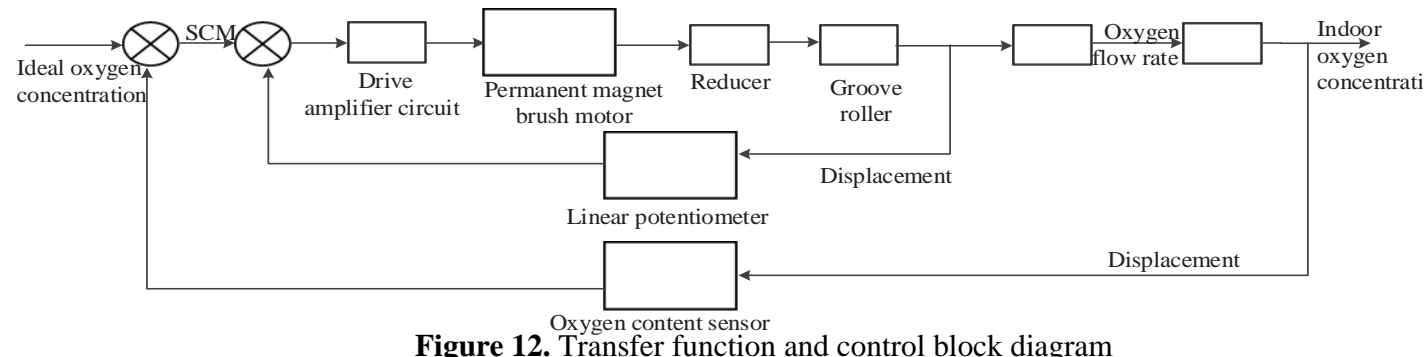

Wherein, $x_{p}$ represents the transfer function between the output displacement $x_{p}$ of the grooved roller and the oxygen concentration $Q_{\text {out }}(\mathrm{s})$, which is also the expression of the core of this design. Fitting through multiple simulation experiments, the optimal fitting expression (6) as follows:

$$
G_{2}(s)=\frac{Q_{o u t}(s)}{S_{o t}(s)}=\frac{0.232 s+5}{0.8 s^{2}+2.765 s+7.762}
$$

\subsection{Simulation \& test}

Through the system control block diagram of the above design, the simulation experiment is carried out by MATLAB, and the displacement curve of the output shaft rotation angle and seal ring axial calculation and test is shown in Figure 13. The relationship between the output oxygen flow and the spool displacement is shown in Figure 14.

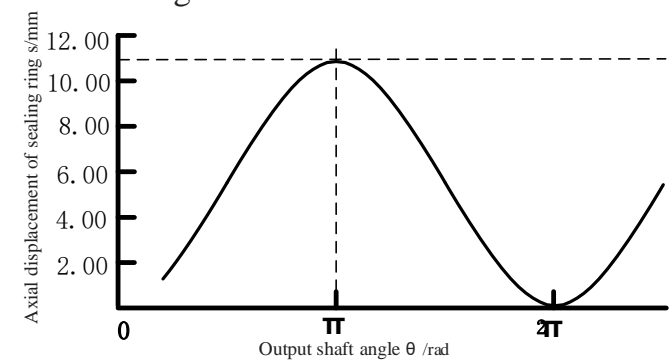

Figure 13. Output angle with seal displacement relationship

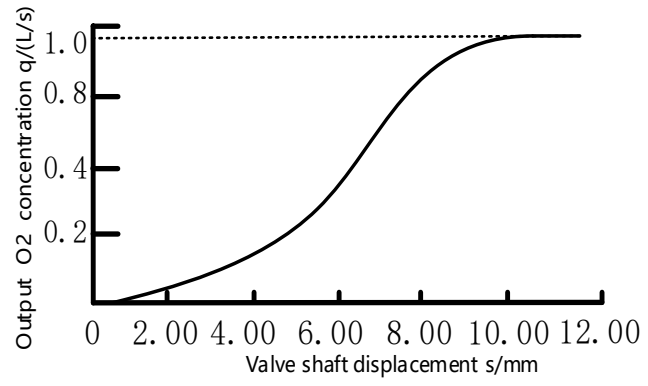

Figure 14. Output oxygen flow vs. valve core displacement

Analysis of the relationship between the spool displacement and the relative drive shaft rotation angle and the output oxygen flow in Figure 13 and Figure 14, shows that there is a nonlinear relationship between the system valve shaft displacement and the output $\mathrm{O}_{2}$ concentration; To test this system under the action of the step target input signal, with 2 cubic meters of limited indoor space to simulate the test of oxygen concentration in the air; As shown in Figure 15, the flow of oxygen output to the indoor environment is a point-source space diffusion of the $u(\stackrel{1}{r}, \mathrm{t})$ function of time $\mathrm{t}$ and space $\stackrel{\mathbf{l}}{\mathrm{r}}=\left(\mathrm{x}_{1}, \mathrm{x}_{2}, \mathrm{x}_{3}\right)$, where analytical solution satisfies the relation (7), where $M_{0}$ is the initial conditions and $\mathrm{M}$ is concentration coefficient.

$$
Q=-\frac{1}{r} e^{-r r} M+M_{0}
$$




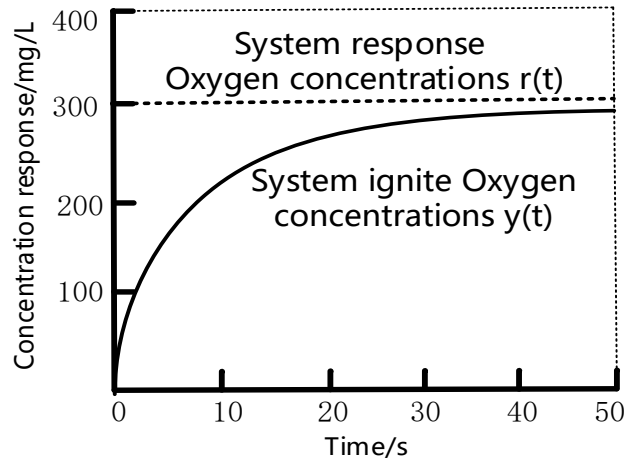

Figure 15. Step target oxygen concentration response curve

According to the normal oxygen content in the air, that is, the oxygen content under the standard condition is $310 \mathrm{mg} / \mathrm{L}$, in the limited space of $2 \mathrm{~m}^{3}$, the system set the target oxygen concentration to $300 \mathrm{mg} / \mathrm{L}$, after $\mathrm{t}=$ 260 s, the system space basically reached the goal Oxygen concentration. Simulation results show that, in line with the actual situation, to meet the design requirements.

\section{Conclusions}

In this dissertation, we improve the design and feasibility of the existing mainstream oxygen supply shut-off valve in China and carry out the simulation of the control system to conclude that the oxygen concentration of the valve design of the valve is in line with the reality, which can provide powerful force for the mine and safety valve system Of the equipment reference; I would like to emphasize the valve guide shaft reciprocating seal and end double seal, "two protective measures" to ensure that its oxygen does not leak, high reliability features. In the innovative structural design of the valve system by adding double closed-loop feedback control, making the valve opening and oxygen flow output is absolutely controllable so that the concentration of oxygen in the final confined space to be high-precision control, the control process is fully automated man-made Operational inconvenience and difficult to control and other issues are well resolved, that the valve to facilitate management, eliminating the need to regulate the manual valve operation, precisely control the room oxygen content, better performance, has good prospects.

\section{References}

1. Xiang gui-sheng, Labor Protection [J]. Emergency Refuge Chamber In The Application of The Mine Disaster Rescue 2006, (9); 92-93.

2. Xue-Guan SONG, Lin WANG, Analysis and Optimization of Rubber Sealing Mechanism Of Ball Valve [J]. Transactions Of Nonferrous Metals Society Of China 2009, (19):220-224.
3. Wang sheng, Mine Emergency Rescue Capsule Technology Abroad [J]. Journal Of Safety Science and Technology 8(2010), 42-46.

4. Zhang Bao-sheng, ChenJia-qing, Sheet Metal Floating Seal Finite Element In Model Study [J] China Petroleum Machinery 6(2011).

5. Cai Yi-gang, Theory Analysis Of Fluid Transmission Line Dynamics. Fluid Transmission Line Dynamics [M] Zhejiang University.

6. Chen Cheng-jun, Combining Face Seal Performance Oriented Assembly Connection Process Design $[\mathrm{J}]$ Journal of Xi'an Jiao Tong University J Xi'an Jiao Tong University 46(2012).

7. Qi Lin, Test Study on the preparation of a Variety of Process Modification Layers On The Surface Of Valve Materials [D]. Master Thesis of Shenyang University of Technology (2012).

8. Lv Pei-wen, Parameters of Practical Valve Design. Practical Valve Design Manual[M]. China Machine PRESS.2012

9. Partial differential equation with boundary with Fourier series and boundary value problems[M] China Machine PRESS.2007 